\title{
INTERPRETACIÓN JURISPRUDENCIAL DE LA OBLIGACIÓN ALIMENTICIA DE LOS ABUELOS.
}

\author{
MARICRUZ GÓMEZ DE LA TORRE ${ }^{*}$
}

\section{Resumen:}

El presente artículo busca analizar, con una perspectiva crítica y eminentemente práctica, la responsabilidad de los abuelos como sujetos subsidiarios de la obligación alimenticia de sus nietos, estimando que debe existir un resguardo no solo del interés superior de los niños, niñas y adolescentes, sino también de los adultos mayores, siendo ambos grupos susceptibles de vulnerabilidad y merecedores de protección por parte del Estado. Para ello, se estudia, en primer lugar, el concepto de alimentos, su fundamento, procedencia y alcance; para luego revisar quiénes son los obligados a pagar estos alimentos, la naturaleza jurídica de la obligación de los abuelos y cómo ha sido ella interpretada por nuestros tribunales de justicia.

\section{Palabras clave:}

Alimentos; Legitimación pasiva; Obligación de los abuelos; Naturaleza jurídica; Obligación subsidiaria.

\begin{abstract}
:
This article seeks to analyze, with a critical and eminently practical perspective, the responsibility of grandparents as subsidiary subjects of the maintenance obligation of their grandchildren, estimating that there should be a safeguard not only of the best interests of children and adolescents,

$1 \quad{ }^{*}$ Profesora Titular de Derecho Civil del Departamento de Derecho Privado de la Facultad de Derecho de la Universidad de Chile. Dirección postal: Avenida Santa María 076, Providencia.7520405. Correo electrónico: maricruz@derecho.uchile.cl.
\end{abstract}


but also also of older adults, both groups susceptible to vulnerability and deserving of protection by the State. For this, the concept of food, its foundation, origin and scope is studied first of all; to then review who are obligated to pay for these foods, the legal nature of the obligation of the grandparents and how it has been interpreted by our courts of justice.

\section{Keywords:}

Foods; Passive legitimization; Obligation of grandparents; Legal nature; Subsidiary obligation.

\section{Introducción.}

En los últimos años, la sociedad chilena ha experimentado cambios profundos en su estructura familiar, provocados por la inestabilidad del matrimonio, el crecimiento de hogares sin una pareja estable -especialmente aquellos encabezados por mujeres solas- y el aumento acelerado de los hogares con una madre sola con hijos. Como consecuencia de esta situación, nos encontramos con madres que crían a sus hijos solas y que requieren del pago de una pensión de alimentos para subsistir dignamente. Como contrapartida, muchos padres no asumen sus obligaciones, evadiendo el pago o directamente no pagando. Esto se constata al verificar el aumento persistente de demandas de pensiones de alimentos y de solicitudes de medidas de apremio para obligar al pago. Según información publicada por el Instituto Nacional de Estadísticas, en el año 2017 ingresaron un total de 148.087 causas en materia de alimentos, correspondiendo al 30\% del total de las demandas ingresadas en materia de familia, convirtiéndola en la materia con más ingresos en los tribunales con competencia familiar. ${ }^{2}$ Asimismo, se ha señalado que a la fecha, el $60 \%$ de los demandados no paga la pensión establecida por los Tribunales de Familia -sea por sentencia o acuerdo- y más de 300 demandados cumplen arresto nocturno como medida de apremio, existiendo alrededor de 70 mil niños que se ven afectados por el no pago de pensiones alimenticias. ${ }^{3}$

Frente esta situación, la ley establece que ante el no pago o un pago insuficiente de la pensión de alimentos, la obligación alimenticia pase a los abuelos. Norma que, si bien pareciera correcta a primera vista, nos lleva a

\footnotetext{
2 Instituto Nacional de Estadísticas, 2017.

3 Sobre este punto, ver: https://www.24horas.cl/nacional/pension-alimenticia-sebusca-crear-el-dicom-de-los-deudores-de-pensiones-3242190.
} 
reflexionar si es ético hacer responder a los abuelos por la irresponsabilidad de los hijos mayores. La situación actual de las personas mayores es compleja,${ }^{4}$ principalmente debido a las dificultades para subsistir provocada por el aumento de la expectativa de vida, las bajas pensiones y su correlato: la necesidad de juntar dinero para comer y comprar medicinas. ${ }^{5}$ En este contexto, se presentó en la Cámara de Diputados un proyecto de ley que libera del pago de alimentos a las personas de la cuarta edad. Señala el proyecto, que el objetivo de la ley es "modificar el artículo 232 del Código Civil, en particular en lo relativo a la obligación subsidiaria de alimentación que recae sobre los adultos mayores 'abuelos', cuando éstos se encuentren en el rango de la cuarta edad, esto es 80 años o más, eximiéndolos de dicha responsabilidad". ${ }^{6}$

En el 2007 publiqué el libro El Sistema Filiativo chileno, que en varios capítulos trataba sobre la regulación de los alimentos. Habiendo transcurrido doce años desde su publicación, es conveniente analizar la evolución del tratamiento jurisprudencial en la obligación alimenticia de los abuelos, porque hoy día hay un enfoque diferente de las obligaciones y necesidades de las personas de la tercera edad.

\section{Derecho de alimentos como derecho humano.}

Uno de los efectos más importantes que emanan de las relaciones de filiación es el derecho de alimentos que tienen los hijos. Esto significa que los padres tienen la obligación de alimentar a sus hijos y ellos un derecho a ser alimentados.

Los Instrumentos Internacionales de Derechos Humanos consideran el derecho a ser alimentado como un derecho humano, el cual debe garantizar a las personas un nivel de vida adecuado. Este principio ha sido recogido por la Declaración Universal de Derechos Humanos (art. 259); el Pacto Internacional de Derechos Económicos, Sociales y Culturales (DESC) (art. 11), y la Convención de los Derechos del Niño (CDN) (art.27), entre otros.

$4 \quad$ Según CENSO 2017 realizado por el Instituto Nacional de Estadísticas (INE) un $16,2 \%$ de la población total en Chile son adultos mayores, subdividiéndose recientemente una brecha entre aquellos de tercera edad, cuyo rango va desde los 65 a los 79 años, y aquellos de cuarta edad, que se encuentran en un tramo aún más vulnerable, cuya edad es desde los 80 años en adelante.

$5 \quad$ Ver Corte de Apelaciones de Coyhaique, 12.02.2016, rol 35-2015; Corte de Apelaciones de Coyhaique 17.01.2011, rol 49-2010.

6 Boletín N ${ }^{\circ} 12552-18$, proyecto presentado por la Diputada Paulina Núñez. 
Por su parte, la Corte Interamericana de Derechos Humanos (CIDH) ha entendido que el derecho a la alimentación se encuentra comprendido en el derecho a la vida. Conforme a su doctrina, el derecho a la vida no se limita a la mera existencia física, sino que comprende el derecho a los medios de subsistencia, a un hogar, a la educación y al esparcimiento. De esta manera, para que las personas puedan desarrollarse en condiciones dignas, es necesario contar con determinadas condiciones materiales de vida. Esto se recoge en la Observación $\mathrm{N}^{\circ} 12$ del Comité de Derechos Económicos Sociales y Culturales, que señala que el derecho a la alimentación se ejerce cuando "todo hombre, mujer o niño, ya sea solo o en común con otros, tiene acceso físico y económico, en todo momento a la alimentación adecuada o a medios para obtenerla" (art.11).

¿Quiénes son los responsables de otorgar el derecho a la alimentación de los niños, niñas y adolescentes (NNA)? La CDN, en su art. $7^{\circ}$, establece el principio de la coparentalidad, en cuanto corresponde a ambos padres la responsabilidad de los hijos comunes; 7 y en el art. 27, prescribe que "a los padres u otras personas encargadas del niño es a quienes les incumbe la responsabilidad primordial de proporcionar, dentro de sus posibilidades y medios económicos, las condiciones de vida que sean necesarias para el desarrollo del niño." Agrega, que "los Estados Partes tomarán todas las medidas apropiadas para asegurar el pago de la pensión alimenticia por parte de los padres u otras personas que tengan responsabilidad financiera por el niño, tanto si viven en el Estado Parte como si viven en el extranjero". Es precisamente dentro de la expresión "otras personas" que se encuentran los abuelos. Esta obligación/responsabilidad nace del parentesco por consanguinidad en línea recta y de segundo grado existente entre abuelos y nietos.

A nivel nacional, debemos preguntarnos cómo nuestra legislación y jurisprudencia han recogido estas directrices, con miras a salvaguardar el derecho de alimentos de los hijos e hijas.

\section{III. ¿Qué es el derecho de alimentos?}

En sentido amplio, Antonio Vodanovic lo define como "el derecho que tienen determinadas personas en estado de necesidad, de exigir alimentos a

$7 \quad$ Principio también consagrado por el Convenio 156 de la Organización Internacional del Trabajo (OIT) sobre trabajadores con responsabilidades familiares ratificado por el estado chileno en 1994. 
otras también determinadas, las cuales están obligadas a proporcionárselos por mandato de la ley o acuerdo de las partes o por un tercero, como el testador que instituye un legado de alimentos". ${ }^{8}$ Por su parte, Mel Greeven señala que:

"son los medios materiales para la existencia física de las personas, esto es, bienestar general de los alimentarios y debe incluirse su integridad psicológica que implica considerar que el menor no puede sufrir las consecuencias de una separación, alterando su status social que ha tenido, lo que implica que debe, en la medida que los ingresos del alimentante lo permitan, continuar desarrollando todas y cada una de las actividades a que estaba acostumbrado, tales como las actividades de entretención y comunicación con sus pares adecuándose de esa manera a las normas contenidas en la CDN".

Jurisprudencialmente, en tanto, se señala que:

"El derecho de alimentos está encaminado a garantizar la subsistencia del alimentario y su fundamento radica, sin duda, en el derecho a la vida. Es sabido que los alimentos son las subsistencias que se dan a ciertas personas, que le permiten subvenir a las necesidades de su existencia, que a lo menos deben cubrir el sustento diario, habitación, vestuario, salud, movilización, vivienda, esparcimiento y educación básica y media del alimentario, hasta el aprendizaje de alguna profesión u oficio". ${ }^{10}$

Más recientemente, la Corte Suprema ha fallado argumentando que:

"La palabra 'alimentos', conforme a su sentido natural y obvio, es aquella que da el Diccionario de la RAE en su quinta acepción, en el sentido que es 'la prestación debida entre parientes próximos cuando quien la recibe no tiene la posibilidad de subvenir a sus necesidades'. Comprende la alimentación, la vestimenta y la habitación, como lo preciso para que la persona que los solicita pueda desarrollarse espiritual y materialmente, lo que abarca la educación y la salud, también actividades recreativas y de esparcimiento, por lo tanto, la obligación de proporcionar alimentos no solo tiene por finalidad conservar o mantener la vida física de la persona del alimentario sino también propender a su desarrollo intelectual y moral.

8 VODANOVIC HAKLICKA, Antonio: Derecho de Alimentos. Editorial LexisNexis, Santiago, 2004. Pág. 4.

9 GREEVEN BOBADILLA, Mel: Derecho de alimentos como derecho humano y apremios para obtener el cumplimiento. Editorial Librotecnia, , Santiago, 2019. Pág. 36.

10 Corte de Apelaciones de Concepción, 13.06.2008, rol 377-2008. En el mismo sentido, Corte Suprema, 22.01.2014, rol 6112-2013. 
Tratándose de los alimentos que se deben a las personas indicadas en el artículo $321 \mathrm{~N}^{\circ} 2$ del Código Civil, esto es, de los descendientes, y de la obligación que recae en sus padres -o en su defecto, en sus ascendientes-, han de permitirles subsistir modestamente de un modo correspondiente a su posición social. En lo que concierne a la obligación de proporcionarles educación, el artículo 323 inciso $2^{\circ}$ señala que comprende la de contribuir a los gastos en que se deba incurrir para que puedan cursar la enseñanza básica y media, también la de una profesión u oficio, con la salvedad, según lo señala el artículo 332 inciso $2^{\circ}$, que se devengará hasta que cumplan veintiún años, a menos que estén estudiando una profesión u oficio, caso en el cual cesa a los veintiocho años"."

Por otra parte, el derecho a demandar alimentos es un derecho personalísimo que se extingue con la muerte del alimentante. Se trata de un derecho irrenunciable, intransferible, intransmisible, inembargable (art. $1618 N^{\circ} 9$ Código Civil) e imprescriptible (art. 2498 Código Civil). Se pueden demandar alimentos en cualquier tiempo, siempre que se cumplan las exigencias legales.

\section{Fundamento del derecho de alimentos.}

El fundamento del derecho de alimentos es plural, se basa en el derecho a la vida, en el principio de la solidaridad familiar y en el interés superior del niño.

La solidaridad familiar se ve como una forma de proteger al cónyuge, conviviente civil e hijos que se encuentra en estado de necesidad. ${ }^{12}$ Claro Solar sostiene que la fuente de la obligación legal de alimentos reside en la solidaridad de familia, en las estrechas relaciones que deben unir a los miembros del mismo grupo familiar.

En cuanto al interés superior del niño, la jurisprudencia ha señalado que:

"Persigue el ejercicio y goce pleno y efectivo de sus derechos y garantías, siendo indiscutible que el derecho a percibir alimentos se enmarca dentro del contexto de la más básica y mínima de las exigencias que el Estado debe tutelar a favor de los niños, prerrogativa que se encuentra íntimamente relacionada al deber de los progenitores de sufragar los gastos

\footnotetext{
11 Ver también Corte Suprema, 31.01.2017, rol 73910- 2016.

12 Ver MEDINA, Graciela: "Principios del Derecho de Familia". En: Revista de Derecho de Familia, volumen IV, N4, 2016. Pág. 109.
} 
de crianza, educación y establecimiento de los hijos, para dotarlos de los medios necesarios para que puedan desarrollarse plenamente en el aspecto espiritual y material, esto es, en todos los ámbitos de su vida". ${ }^{13}$

Agregando, también, que:

"Para interpretar adecuada y correctamente tales preceptos debe acudirse al principio del interés superior del niño, que persigue el ejercicio y goce pleno y efectivo de sus derechos y garantías, siendo inconcuso que el derecho a percibir alimentos se enmarca dentro del contexto de la más básica y mínima de las exigencias que el Estado debe tutelar a favor de los niños, prerrogativa que se encuentra íntimamente relacionada al deber de los progenitores de sufragar los gastos de crianza, educación y establecimiento de los hijos, para dotarlos de los medios necesarios para que puedan desarrollarse plenamente en el aspecto espiritual y material, esto es, en todos los ámbitos de su vida". ${ }^{14}$

\section{V. ¿A quién se deben alimentos?}

Para demandar alimentos se requiere de un título. En esta línea, el art. 321 del Código Civil establece que se deben alimentos al cónyuge, a los descendientes, a los ascendientes, a los hermanos y al que hizo una donación cuantiosa si no hubiere sido rescindida o revocada.

Cuando la ley habla de descendientes se refiere a los hijos, nietos, bisnietos o cualquiera persona que descienda de ellos. En consecuencia, el hijo puede demandar alimentos a su padre o madre y viceversa. No obstante, cuando el alimentario tiene varios títulos de los enumerados en el art. 321 del Código Civil, solo podrá hacer uso de uno de ellos; ${ }^{15}$ de tal forma que, entre varios ascendientes o descendientes, debe recurrirse a los del grado más próximo. Entre los del mismo grado, como también entre varios obligados por un mismo título, el juez distribuirá la obligación

\footnotetext{
13 Corte Suprema, 08.02.2017, rol 4345-2016.

14 Corte Suprema, 15.12.2015, rol 8129- 2015. Considerando $8^{\circ}$.

15 RDJ Volumen LXXVIII, Tomo I, $2^{\mathrm{a}}$ parte, Sección $2^{\mathrm{a}}$, 1981. Considerando $9^{\mathrm{o}}$ :

"Que, de acuerdo, a lo que preceptúa el artículo 326 en relación con el artículo 321 del Código Civil, aquellas personas que tienen derecho a pedir alimentos podrán hacer valer para ello el título enumerado en el artículo 321 de ese cuerpo legal, en el orden que establece la primera disposición citada y sólo en el caso de insuficiencia del título preferente podrá recurrirse a otro".
} 
en proporción a sus facultades. ${ }^{16}$ Habiendo varios alimentarios respecto de un mismo deudor, el juez distribuirá los alimentos en proporción a las necesidades de aquellos. En el caso de insuficiencia de todos los obligados por el título preferente, podrá recurrirse a otro. ${ }^{17}$

En consecuencia, solo cuando los padres no puedan asumir el pago de la pensión alimenticia, la obligación pasará, en primer lugar, a los abuelos de la línea del padre o madre que no provee; y, en subsidio de estos, a los abuelos de la otra línea. ${ }^{18}$ Por su parte, el art. 232 del Código Civil prescribe que la obligación de alimentar al hijo que carece de bienes pasa, por falta o insuficiencia de los padres, a sus abuelos, por una y otra línea, conjuntamente. El art. $3^{\circ}$, inc. $5^{\circ}$, de la Ley $\mathrm{N}^{\circ} 14.908$, finalmente, establece: "cuando los alimentos decretados no fueren suficientes para solventar las necesidades del hijo, el alimentario podrá demandar a los abuelos, de conformidad a lo que establece el artículo 232 del Código Civil".

Analizando las normas precedentes, cabe preguntarse: ¿Qué significa que el art. 232 del Código Civil diga "pasa a los abuelos"? La palabra "pasa" de este artículo alude a que la obligación de alimentar de los primeros obligados (los padres) se traslada, traspasándose a los abuelos. En este sentido, la Corte Suprema ha señalado:

"El artículo 232 inciso primero, que el recurso da por infringido, consigna que la obligación de alimentar al hijo que carece de bienes, pasa por la falta o insuficiencia de ambos padres, a sus abuelos, por una y otra línea conjuntamente. En una perspectiva puramente semántica, valga recordar que para el diccionario de la Real Academia de la Lengua el verbo 'pasar' significa 'conducir de un lugar a otro' (1), 'Mudar, trasladar a otro lugar, situación o clase' (2), 'Cruzar de un lugar a otro' (3), 'Enviar, transmitir' (4), 'Traspasar' (6), 'Transferir o trasladar algo de una persona a otra' (9), 'Extenderse o comunicarse de unos a otros' (31). Cuando el artículo 232 utiliza la forma verbal 'pasa' quiere decir que la obligación de alimentar se trasladó a otro u otros, en este caso a los abuelos; que se mudó;

$16 \quad$ FALLOS DEL MES No 157 p. 310 . "Demandado uno de los abuelos para que proporcione alimentos a un nieto suyo, no puede pretender que por estar conjuntamente obligados todos los abuelos, debe paralizarse o suspenderse el juicio hasta que la demanda se dirija simultáneamente en contra de todos ellos; sin perjuicio del derecho del alimentante para alegar que existen otros ascendientes de su grado y que deben regularse los alimentos que se exigen en relación, a las facultades de todos los obligados conjuntos".

17 Ver GÓMEZ DE LA TORRE VARGAS, Maricruz: El sistema filiativo chileno. Editorial Jurídica de Chile, Santiago, 2007. Pág. 194.

18 Ver Corte de Apelaciones de Santiago, 21.08.2012, rol 43-2012. 
que se transmitió a ésos; que se les extendió o comunicó. Si eso no es inexacto, resta determinar el momento que la prevención legislativa tiene en cuenta para la consumación de tal traslación. Al efecto, su circunstancia gatilladora está dada por el complemento 'por la falta o insuficiencia de ambos padres". ${ }^{19}$

\section{Naturaleza jurídica de la obligación de los abuelos.}

La obligación de otorgar alimentos a los nietos es una obligación legal, subsidiaria y simplemente conjunta.

Es una obligación legal,,$^{20}$ porque es la ley la que la crea; su origen está en ella y el título que permite demandar alimentos está claramente encuadrado en los arts. $321 \mathrm{~N}^{\circ} 2 ; 326 \mathrm{~N}^{\circ} 3,232$ del Código Civil y art. $3^{\circ}$ de la Ley $\mathrm{N}^{\circ} 14.908$.

Es subsidiaria a la de los deudores preferentes (padres), por cuanto su nacimiento y exigibilidad solo tiene lugar cuando se presentan las hipótesis legales, relacionadas con el incumplimiento o cumplimiento imperfecto de los alimentos por el principal obligado. En este sentido, la Corte Suprema ha señalado que:

"La obligación de proporcionar alimentos que la ley establece respecto de los abuelos, de una u otra línea, se encuentra supeditada a la verificación de los presupuestos que ella misma establece. En efecto, esta responsabilidad sólo puede reclamarse respecto de las personas indicadas, cuando los alimentos decretados no fueren pagados o no fueren suficientes para solventar las necesidades del hijo, es decir, ante la falta o insuficiencia de los progenitores, como principales y naturales obligados a la mantención de sus hijos. Si bien el deber legal de proporcionar alimentos que recae sobre los abuelos respecto de sus nietos, como presupuesto esencial, constituye una obligación subsidiaria, en términos tales que el nacimiento y exigibilidad de la misma sólo tiene lugar cuando se presentan las hipótesis

19 Corte Suprema 04.08.2014, rol 1617-2014. Énfasis añadido.En igual sentido, Corte Suprema, 30.11.2006, rol 5356- 2013, que señala: "La obligación de los abuelos de proporcionar alimentos a sus nietos aparece establecida en el artículo 232 del Código Civil, el que dispone: 'La obligación de alimentar al hijo que carece de bienes pasa, por la falta o insuficiencia de ambos padres, a sus abuelos por una u otra línea conjuntamente. En caso de insuficiencia de uno de los padres, la obligación indicada precedentemente, pasará en primer lugar a los abuelos de la línea del padre o madre que no provee y, en subsidio de éstos, a los abuelos de la otra línea".

20 Ver Corte Suprema, 21.04.2016, rol 19.358-2016. 
legales, relacionadas con el incumplimiento o cumplimiento imperfecto de los alimentos por el principal obligado, ello no significa que la contribución a la carga por el resto del o los obligados, deba determinarse únicamente sobre la base de lo que el primero se encontraba obligado a pagar, sino que deben considerarse las necesidades del o los alimentarios y la capacidad del o los demás obligados, cuando precisamente, como ocurre en la especie, se trata de salvar la situación de insuficiencia en el aporte del alimentante y así determinar la parte y forma en que el deudor concurre a la prestación. A tal conclusión se arriba teniendo en consideración, la naturaleza esencial que presenta el derecho-deber de proporcionar alimentos y el principio del interés superior del niño y de la solidaridad familiar". ${ }^{21}$

Más recientemente, la Corte Suprema ha fundado su resolución en el siguiente argumento:

“Atendido el carácter subsidiario de la obligación alimentaria de los abuelos, debe concluirse que es correcta la exclusión de la menor de las hijas de la demandante, pues al no haberse decretado jamás una pensión a su favor de cargo del padre, mal puede declararse la insuficiencia que fundamenta la acción deducida". ${ }^{22}$

Finalmente, es simplemente conjunta, porque cada uno de los abuelos debe concurrir solo a su parte o cuota de la prestación; ello significa que, entre varios obligados por un mismo título, el juez debe distribuir en proporción a su situación económica (facultades) y necesidades de los alimentarios (nietos). El abuelo que tenga una mayor capacidad económica deberá contribuir en una proporción mayor. ${ }^{23}$ Así, la Corte Suprema ha señalado que:

"En la especie, si bien la ley contempla y regula la forma y condiciones en que la obligación de prestar alimentos pasa de los padres a los abuelos, especifica claramente que se trata de una obligación simplemente conjunta, entendiéndose por tal aquella en que cada uno de los deudores debe concurrir sólo a su parte o cuota de la prestación". ${ }^{24}$

\footnotetext{
21 Corte Suprema, 30.10.2012, rol 2416-2012. Considerando $9^{\circ}$. Énfasis añadido.

22 Corte Suprema, 25.01.2018, rol 39.744-2017. Énfasis añadido.

23 Véase SCHMIDT HOTT, Claudia y VELOSO VALENZUELA, Paulina: La filiación en el Nuevo Derecho de Familia. Editorial Lexis Nexis, Santiago, 2001. Pag. 386; VODANOVIC, ob. cit. Pág. 81; y NÚNEZ JIMÉNEZ, Carlos A.: "La obligación de alimentos de los abuelos. Estudio Jurisprudencial y dogmático". En: Revista Chilena de Derecho Privado, ํ21, 2013. Pág. 59.
}

24 Corte Suprema, 30.11.2006, rol 5356-2006. Énfasis añadido. 


\section{Interpretación de los arts. 232; 321 N²; 326 N³ del Código Civil y $3^{\circ}$ de la Ley 14.908.}

Ante la demanda de alimentos en contra de los abuelos, la interpretación de los tribunales de los arts. 232; $321 \mathrm{~N}^{\circ} 2 ; 326 \mathrm{~N}^{\circ} 3$ y $3^{\circ}$ inc. final de la Ley $\mathrm{N}^{\circ} 14.908$ sobre Pago de Pensiones Alimenticias ha sido contradictoria. Por una parte, se considera que la obligación, al ser subsidiaria, debe aplicarse restrictivamente, probándose la falta o insuficiencia del título preferente. Y por otro lado, se estima que procede la acción judicial directa en contra de los abuelos, imponiéndose la obligación de pagar alimentos a favor de sus nietos, tanto en el caso de falta del título preferente como por insuficiencia del título preferente.

1. Sentencias en que se requiere insuficiencia del título preferente.

¿Qué se entiende por insuficiencia? La Corte Suprema ha señalado que:

"la expresión insuficiencia del art. 232 del Código Civil debe ser entendida en un sentido amplio, comprensivo de situaciones de carencia de bienes o imposibilidad absoluta de servicio del obligado principal, como la de no pago o renuencia en pagar la pensión alimenticia, en armonía con los artículos $3^{\circ}$ de la Ley sobre Pago de Pensiones Alimenticias y 27 de la CDN", ${ }^{25}$

Igualmente, la Corte de Apelaciones de Coyhaique, aludiendo al carácter subsidiario antes enunciado, ha fallado que:

"El deber de alimentos de los ascendientes es de carácter subsidiario, de excepción, previo cumplimiento de determinados requisitos, específicamente, la insuficiencia de los padres, entendida en el amplio concepto citado, en consecuencia, la interpretación del citado artículo 3 de la Ley 14.908, en lo que a la presunción de solvencia se refiere, debe realizarse restrictivamente", ${ }^{26}$

En tanto, la Corte de Apelaciones San Miguel ha resuelto que:

“Que, el Código Civil no define la expresión 'insuficiencia' por lo que debe hacerse una interpretación armónica del inciso final del artículo 3 de la ley 14.908, artículo 232 del Código Civil y artículos $3^{\circ}$ y 27 de la

25 Corte Suprema, 13.01.2016, rol 10431-2015. En igual sentido, Corte Suprema, 15.12.2015, rol 8129-2015, que señala: "La voz 'insuficiencia' debe comprenderse en un sentido amplio, que incluya no sólo la situación de carencia de bienes o imposibilidad absoluta del alimentante preferente para hacerse cargo de su obligación, sino también el simple hecho del no pago, lo que también entraña la mera renuencia y rebeldía en su cumplimiento".

26 Corte de Apelaciones de Coyhaique 17.01.2011, rol 49-2010. 
Convención sobre Derechos del Niños, utilizándola en el sentido amplio, comprendiendo, entre otros, el no pago o renuencia a pagar alimentos". ${ }^{27}$

Como se ha señalado, la obligación de otorgar alimentos que la ley impone a los abuelos -sean paternos o maternos- se encuentra condicionada a la verificación de los presupuestos establecidos en los arts. 232 y 326 del Código Civil y $3^{\circ}$ inc. final de la Ley $\mathrm{N}^{\circ} 14.908$, de donde resulta que su responsabilidad solo puede reclamarse cuando los alimentos decretados no fueren pagados o no fueren suficientes para solventar las necesidades del alimentario. ${ }^{28}$

Del análisis de los arts. 321 y 326 del Código Civil, en tanto, se concluye que hay un orden de prelación respecto de los obligados a dar alimentos y, en caso de falta de título preferente (los padres), resulta aplicable la norma del art. 232, que remite a la insuficiencia.

Por su parte, el art. 326 del Código Civil y el art. $3^{\circ}$ de la Ley sobre Pago de Pensiones Alimenticias exigen que, para proceder en contra de los abuelos, existan alimentos decretados y que estos no fueren pagados o fueren insuficientes.

Además de lo anterior, se ha exigido acreditar que las facultades económicas de uno o ambos padres son insuficientes o carecen de medios para proporcionarlos. En tal sentido, una sentencia de la Corte de Apelaciones de Valparaíso ha señalado que:

"no se advierte la insuficiencia del padre para proporcionar alimentos a sus hijos menores ya que los otorga de acuerdo a sus facultades económicas; lo que ocurre es que la madre, que demanda por ellos, pretende solventar no sólo las necesidades relativas a alimentación, educación, vivienda y salud sino también una serie de otros gastos derivados de eventos sociales, lo que obviamente, escapa a la naturaleza que debe tener la obligación de prestar alimentos". ${ }^{29}$

Por lo tanto, podemos concluir que los abuelos no pueden ser demandados directamente, sino cuando los alimentos decretados no fueren pagados o fueren insuficientes. Si el abuelo no cumple o cumple insuficientemente con la obligación alimenticia, o no tiene los medios para

27 Corte de Apelaciones San Miguel Sentencia de 01.08.2011, Rol 449-2011, considerando $2^{\circ}$. Ver en igual sentido, Corte de Apelaciones de Concepción, 23.11.2009, rol 451-2009.

29 Corte de Apelaciones de Valparaíso, 18.06.2015, rol 309-2015. Considerando $10^{\circ}$. 
proporcionar alimentos a su nieto, la obligación pasará a los abuelos de la otra línea. ${ }^{30}$

En todo caso, cabe advertir que si cambia la situación del titular de la obligación alimenticia, cesa la obligación de los abuelos. Así lo ha reconocido la Corte Suprema en un fallo donde se señala:

"que para acoger la demanda de cese de alimentos interpuesta por los abuelos paternos de la alimentaria, el tribunal tuvo en consideración que, a la fecha, la pensión alimenticia a la que se encuentra condenado el padre es pagada mediante retención por parte de su empleador, de modo tal que se vislumbra estabilidad económica del padre al prestar servicios remunerados y pagar la pensión bajo una modalidad que garantiza su cumplimiento, por lo que no puede considerarse que se mantiene la inestabilidad del padre, tenida a la vista al momento de acordar la pensión alimenticia a la que se encuentran condenados los demandantes". ${ }^{31}$

Para que los abuelos asuman el pago de la pensión alimenticia, la jurisprudencia mayoritariamente, en razón del mandato del artículo $3^{\circ}$ de la ley $\mathrm{N}^{\circ} 14.908$, exige que los alimentos estén regulados previamente respecto del padre o madre alimentante, que estos no fuesen pagados o no fuesen suficientes ${ }^{32}$ para cubrir las necesidades de los alimentarios y que la insuficiencia conste en sentencia ejecutoriada. Asimismo, se ha sentenciado que debe presentarse una declaración de falta de pago, o de insuficiencia $\mathrm{y}$, además, que el demandante debe haber agotado todos los medios que establece la ley para obtener el cumplimiento de la obligación por parte del padre o madre deudor. ${ }^{33}$

En tales términos, la Corte Suprema ha resuelto argumentando lo siguiente:

"Que, en este sentido, cabe tener presente que el padre de las alimentarias no ha sido demandado para contribuir de mayor manera con su obligación legal de proporcionar alimentos a sus hijas, de manera que no puede sino concluirse que en la especie no se cumplen los presupuestos que la ley ha previsto para los efectos de hacer responsable de la obligación alimenticia a la abuela paterna, puesto que no se configura el requisito básico de haberse constatado la insuficiencia e imposibilidad de obtener por

30 Ver GÓMEZ DE LA TORRE VARGAS, ob. cit. Pags. 513 y 514; Corte de Apelaciones de San Miguel, 20.11.2015, rol 793-2015.

31 Corte Suprema, 10.06.2014, rol 9596-2014.

32 Ver Corte de Apelaciones de Santiago, 27.12.2010, rol 1101.2010.

33 Ver Corte de Apelaciones de Coihaique, 12.02.2016, rol 35-2015. 
parte del padre una contribución mayor a aquélla que realiza, al no haber instado ella en este sentido a través de las formas que la ley contempla, limitándose a accionar nuevamente en contra de la demandada, respecto de la cual la obligación alimenticia en relación a sus nietas, es subsidiaria a la de los padres, quienes son los principales obligados". ${ }^{34}$

La Corte de Apelaciones de Coyhaique, por su parte, ha planteado que:

"La jurisprudencia nacional sobre demandas de alimentos en contra de los abuelos ha sido vacilante en la interpretación de los arts. 232, $321 \mathrm{~N}^{\circ} 2$, $326 \mathrm{~N}^{\circ} 3$ e inc. final del Código Civil, $3^{\circ}$ inc. final de la Ley sobre Pago de Pensiones Alimenticias y $3^{\circ}$ y 27 de la $\mathrm{CDN}$, pues una parte estima que es procedente la acción judicial directa en contra de los abuelos, a fin de que a estos se imponga la obligación de pagar alimentos a favor de sus nietos, en caso de falta del título preferente y también por insuficiencia del título preferente, mientras que otra dice que tal obligación, al ser subsidiaria debe aplicarse restrictivamente. Ahora bien, según es posible observar de los arts. 321 y 326 del Código Civil, hay un orden de prelación respecto de los obligados a dar alimentos y en caso de falta de título preferente resulta aplicable la norma del art. 232 en tanto de la insuficiencia, además, el art. 326 inc. final, e inc. final del art. $3^{\circ}$ de la Ley sobre Pago de Pensiones Alimenticias, esta última exigiendo para proceder en contra de los abuelos, que existan alimentos decretados y que estos no fueren pagados o fueren insuficientes (considerando $8^{\circ}$ ). En la especie, en que se ha accionado en contra de los abuelos paternos por insuficiencia de los alimentos pagados por el padre, la demandante debe arbitrar todos los medios para obtener del padre del menor alimentario, primer título preferente, una pensión de alimentos que cubra todas sus necesidades; y, conforme se desprende del mérito de los autos, no consta que el padre alimentante haya sido demandado para contribuir en mayor medida con su obligación legal de proporcionar alimentos a su hijo, de manera que no puede sino concluirse, que no se cumplen los presupuestos que la ley ha previsto para los efectos de hacer responsables de la obligación alimenticia a los abuelos paternos, pues no se configura el requisito básico de haberse constatado la insuficiencia e imposibilidad de obtener por parte del padre una contribución mayor a aquélla que realiza, al no haberse instado por ella en este sentido, a través de las formas que la ley contempla, entendiendo que la obligación alimenticia de los abuelos, en relación a su nieto, es subsidiaria a la de los padres, quienes son los principales obligados. En efecto, previamente a 
perseguir a los abuelos se requiere del agotamiento del título preferente, demandando a éste por aumento de alimentos, cuestión que no ha ocurrido en autos". ${ }^{35}$

La misma Corte sustentó su resolución afirmando que:

"En la especie, la actora, teniendo la certeza del monto de alimentos devengados e incumplidos, en vez de instar por el cumplimiento del monto adeudado, sea total o por parcialidades, en la forma que establecen los artículo 12 y siguientes de la Ley sobre Pago de Pensiones Alimenticias, optó por demandar de alimentos al abuelo paterno del menor, habiendo transcurrido tan solo un breve tiempo desde que el padre del menor había efectuado en tres ocasiones abonos a la deuda, sin esperar la total insuficiencia económica del padre del menor, que -como se dijo- estaba efectuando abonos, accionando contra el abuelo paterno, cercano a los ochenta años de edad y que vive de una pensión ascendente a cien mil pesos. Por consiguiente, si bien la ley autoriza que se demande a los abuelos ante la insuficiencia de ambos padres para sufragar los gastos de crianza, educación y establecimiento de los hijos, lo cierto es que no conste en autos tal circunstancia, esto es, la insuficiencia de ambos padres". ${ }^{36}$

También se discute si dentro de las exigencias para que la obligación alimenticia pase a los abuelos, está la de que el demandante deba recurrir previamente a los apremios al demandado. Esta exigencia no está contenida en los arts. 232, ni en el art. $3^{\circ}$, inc. final de la Ley No14.908. Lo que tales normas exigen, como se ha visto, es que haya insuficiencia o no pago de la pensión de alimentos, sin que se haga referencia alguna a los apremios. De exigirlos, se estaría aumentando los requisitos que requiere la ley para configurar la hipótesis de las normas antes señaladas. Al respecto, la Corte Suprema ha señalado:

"Que es un hecho de la causa el incumplimiento histórico del padre de la obligación de contribuir al pago de las necesidades y alimentos del hijo, desde que se le impuso judicialmente, manteniendo una deuda impaga por dicho concepto, a partir del año 2012. A lo anterior se debe agregar la precaria situación económica de la madre y del niño, hecho que quedó acreditado por los jueces del fondo. En consecuencia, a juicio de

35 Corte de Apelaciones de Coyhaique, 10.06.2016, rol 9-2016. Considerando $9^{\circ}$. Énfasis añadido.

36 Corte de Apelaciones de Coyhaique, 12.02.2016, rol 35-2015. Considerando $6^{\circ}$. Énfasis añadido. En el mismo sentido, véase: Corte Suprema Sentencia, 25.01.2018, rol 39.744-2017; y Corte de Apelaciones de Rancagua, 29.10.2018, rol 310-2018. 
esta Corte, se configura plenamente el supuesto que hace surgir el deber jurídico del abuelo paterno de contribuir al sustento del niño, de acuerdo a sus facultades (considerando $9^{\circ}$ ). Que no de otra manera debe entenderse por configurada la hipótesis de la insuficiencia a que se refieren los artículos $3^{\circ}$, inciso final, de la Ley $\mathrm{N}^{\circ} 14.908,232$ y 302 del Código Civil, pues no contienen elemento alguno que permita entender que dicho concepto se encuentra sujeto al cumplimiento de exigencias como las que pretende el fallo impugnado, desde que el uso de los mecanismos de apremio para obtener el pago de lo adeudado en materia de alimentos, corresponde a una herramienta procesal, que en caso alguno, constituye un requisito para configurar la hipótesis de las normas antes referidas, de manera que basta para acreditar la insuficiencia que permita el paso de la obligación del padre alimentante principal a los abuelos, que su contribución, conforme a lo que en derecho le corresponde, es parcial e incompleta en relación a las necesidades del alimentario, situación acreditada en autos. Como ya se ha señalado por esta Corte, la obligación de proporcionar alimentos que la ley establece respecto de los abuelos, de una u otra línea, procede cuando los alimentos decretados no fueren pagados o no fueren suficientes para solucionar las necesidades del hijo (Ingreso $\mathrm{N}^{\circ} 2416$ 12), esto significa, que la voz "insuficiencia" debe comprenderse en un sentido amplio, que incluya no sólo la situación de carencia de bienes o imposibilidad absoluta del alimentante preferente para hacerse cargo de su obligación, sino también el simple hecho del no pago, lo que también entraña la mera renuencia y rebeldía en su cumplimiento". ${ }^{37}$

Asimismo, la Corte Suprema también ha resuelto que:

"En la especie, establecido, por una parte, que los alimentos decretados judicialmente no han sido pagados por el padre de los alimentarios $\mathrm{y}$, por otra, que en contra de aquél se han despachado órdenes de apremio e iniciado un juicio ejecutivo para obtener el cumplimiento forzado de lo adeudado, se concluye que concurre el sustento que hace surgir el deber jurídico del abuelo paterno demandado de contribuir al sustento de sus nietos y de acuerdo a sus facultades. Exigir a la demandante -madre de los alimentarios- que ante la renuencia del progenitor a cumplir su obligación legal agote los medios al efecto, importa imponer una exigencia que no está establecida en la ley y que genera una dilación en la satisfacción de las necesidades de los alimentarios, conculcándose, con ello, el derecho 
que les asiste a obtener de su abuelo paterno los recursos económicos necesarios para su manutención". ${ }^{38}$

Si se llega a un acuerdo -vía conciliación- entre el obligado principal y la madre del nieto, ¿procede el cese de pago de alimentos por parte del abuelo? Al respecto, la Corte ha señalado que no procede reclamar su extinción ya que aún existe una deuda vigente impaga bajo el título de alimentos impagos. Así:

"En la especie, resultó acreditada la primera circunstancia, pues actualmente existe una deuda impaga por parte del padre del alimentario, que sin duda va en detrimento de su mantención, lo que configura la situación prevista por la ley para que opere la responsabilidad alimenticia subsidiaria, no siendo atendible la alegación del abuelo demandante de cese de alimentos en el sentido que dicha deuda se extinguió con el mérito de la conciliación arribada por el alimentante principal con la demandada. En efecto, siendo la obligación que pesa sobre el abuelo una de origen legal, que surge en la medida que se acrediten las circunstancias ya reseñadas, no puede reclamarse su extinción si aún existe una deuda vigente bajo el título de alimentos impagos". ${ }^{39}$

2. Sentencias en que se ha permitido la acción directa contra los abuelos.

Como se señaló previamente, hay situaciones en que los tribunales han aceptado que se pueda entablar acción directa contra los abuelos en caso de falta de título preferente o por insuficiencia de este. Estas situaciones son como la del padre estudiante universitario con crédito fiscal y sin trabajo; o la de muerte del padre alimentante.

Sin embargo, tales casos especiales no denotan como regla la de la procedencia directa de la acción, pues los fallos que han aceptado esta hipótesis se justifican por situaciones excepcionales de vulnerabilidad económica.

Así, es posible observar en un fallo de la Corte de Apelaciones de Chillán el siguiente argumento:

"Que, en estos autos la parte demandante ha demandado a los abuelos paternos, de conformidad con lo dispuesto en el artículo 232 del Código Civil, no fundándose, por lo tanto, en el artículo 3 de la Ley 14.908,

$38 \quad$ Corte Suprema, 06.03.2017, rol 76375-2016. Considerando $4^{\circ}$.

39 Corte Suprema, 16.03.2017, rol 76375-2016. Considerando $6^{\circ}$. 
razón por la cual la alegación de la defensa, en el escrito de apelación, en el sentido de que sus representados no son sujetos pasivos de la acción deducida, carece de todo asidero legal. Pretender que para demandar a los abuelos paternos es necesario que siempre existan alimentos decretados por sentencia judicial y que éstos no fueran pagados o no fueren suficientes, significaría, lisa y llanamente, de una parte, desconocer el tenor literal del artículo 232 del Código Civil y, por la otra, aplicar el inciso final del artículo 3 de la Ley 14.908 a una situación totalmente distinta de la señalada por el legislador. $8^{\circ}$.- Que, la legislación civil relativa a menores tiene como fin último el interés superior del niño, razón por la cual, de exigirse que en un juicio aparte se establezca la insuficiencia económica del padre para proporcionar alimentos a sus hijos menores, se estaría vulnerando tal principio, como quiera que ello atenta contra la inmediatez y la urgencia de proporcionar tales alimentos, ya sean provisorios o definitivos". ${ }^{40}$

Corte Suprema, por su parte, ha realizado el siguiente razonamiento:

"Que se debe tener presente que, en la sentencia de primera instancia, reproducida por la de segunda, se estableció como hecho de la causa que las necesidades de los alimentarios ascenderían a $\$ 1.441 .832$, y que el padre fue condenado a pagar una pensión de alimentos de $\$ 120.000$. En consecuencia, se configura plenamente el supuesto que hace surgir el deber jurídico de los abuelos paternos de contribuir al sustento de los hijos, de acuerdo a sus facultades (...) Que, por último, el hecho que no se haya demandado de aumento de la pensión de alimentos al padre en otro procedimiento, no es argumento válido para estimar que se incurrió en una errada interpretación de las normas transcritas y que se denuncian conculcadas, porque el presupuesto que permite demandar a los abuelos se configura por el hecho de acreditarse que 'los alimentos no son suficientes para solventar las necesidades del hijo', como lo señala en forma perentoria el artículo 3, inciso final, de la Ley $\mathrm{N}^{\circ}$ 14.908; hipótesis que también establece el artículo 232 del Código Civil, ya que autoriza que se demande a los abuelos ante la 'insuficiencia de ambos padres' para sufragar los gastos de crianza, educación y establecimiento de los hijos, situación que se configura cuando es exigua la pensión de alimentos que deben pagar los progenitores; hipótesis que, como se señaló, se tuvo por establecida en la sentencia de manera inamovible, de manera que se trata de una cuestión 
que no puede afectar el derecho de aquellos a recabarla de sus abuelos paternos ante la insuficiencia de la pensión que el padre paga". ${ }^{41}$

Igualmente, la Corte Suprema ha resuelto que:

"Del análisis de las disposiciones citadas (art. 232 y 321 CC) se desprende que la obligación de proporcionar alimentos que la ley establece respecto de los abuelos, de una u otra línea, se encuentra supeditada a la verificación de los presupuestos que ella misma dispone. En efecto, esta responsabilidad sólo puede reclamarse respecto de las personas indicadas cuando los alimentos decretados no fueren pagados o no fueren suficientes para solventar las necesidades del hijo, es decir, ante la falta o insuficiencia de los progenitores como principales y naturales obligados a la mantención de sus hijos. En este sentido, cabe tener presente que los presupuestos fácticos establecidos en el fallo impugnado, como son la muerte del padre de la alimentaria, que éste era quien proveía a su manutención y que la madre con los ingresos que percibe no alcanza a cubrir sus necesidades, satisfacen las hipótesis legales que autorizan para accionar en contra de los abuelos, ante la evidente falta del progenitor y la insuficiencia de la madre sobreviviente por la situación económica en que se encuentra. De esta manera no puede sino concluirse que en la especie se cumplen los presupuestos que la ley ha previsto para los efectos de hacer responsable de la obligación alimenticia a la abuela paterna, la demandada, puesto que se configura el requisito básico de haberse constatado la falta por un lado del padre y por otro la insuficiencia de la madre, como principales obligados al cumplimiento de la obligación de proporcionar alimentos a la hija". ${ }^{42}$

No obstante lo anterior, cabe también señalar que en doctrina se ha afirmado en contrario. Así, Núñez Jiménez sostiene que sí es procedente la acción judicial directa. En este sentido, señala que el inc. $2^{\circ}$ del art.232 "se refiere solo a la insuficiencia, estimamos que la norma también tiene aplicación tratándose de la falta del título preferente, razón por la que también puede demandarse directamente a los abuelos por la línea del padre que falte y debería proveer". ${ }^{43}$

\footnotetext{
$41 \quad$ Corte Suprema, 08.02.2017, rol 4345-2016. Considerandos $8^{\circ}$ y $9^{\circ}$.

42 Corte Suprema, 29.02.2012, rol 1044-2011.

43 NÚNEZ JIMÉNEZ, ob. cit. Pág. 86.
} 


\section{Conclusiones}

Antes de entrar directamente a las conclusiones, debo señalar que en los doce años transcurridos desde que publiqué el libro Nuevo Sistema Filiativo ha aumentado el número de personas de la tercera edad que se encuentran en situaciones de vulnerabilidad. De ahí que haya una mayor preocupación por la situación de este grupo etario.

Si bien es cierto que nuestra legislación vela por el interés superior de los niños, niñas y adolescentes y, que el Estado ha suscrito tratados y convenciones en favor de estos, es menester la equidad en ambos grupos susceptibles de vulnerabilidad. Es por ello que estimo necesario establecer el deber social de salvaguardarlos de manera proporcional, y así como nuestra legislación establece diversos derechos y protege a los NNA -instaurando la presunción de solvencia económica del padre o madre, por ejemplo-, también nuestra legislación debería proteger a los adultos mayores y de ahí que el proyecto de ley que exonera de esta obligación a los adultos de la cuarta edad está en la línea correcta. ${ }^{44}$

Del análisis de la jurisprudencia y doctrina se constata una mayor incorporación del interés superior del niño para justificar en los fallos que la obligación alimenticia pase a los abuelos.

Se continúa con la interpretación de que, para que proceda la obligación alimenticia de los abuelos, estos deben solicitarse previamente al padre. No pueden demandarse directamente, pues se trata de una obligación subsidiaria. Solo procede, en consecuencia, cuando los alimentos decretados por sentencia judicial no fueren pagados por el padre/madre, o cuando no fueren suficientes (art. 232 del Código Civil y $3^{\circ}$ de la Ley 14.988).

Sin embargo, los tribunales han empezado a ser más proclives a aceptar la acción directa contra los abuelos en caso de falta de título preferente o por insuficiencia de este, pero solo en casos excepcionales, por situaciones vulnerabilidad económica y urgencia del alimentado. 


\section{Bibliografía.}

GÓMEZ DE LA TORRE VARGAS, Maricruz: El sistema filiativo chileno. Editorial Jurídica de Chile, Santiago, 2007.

GREEVEN BOBADILLA, Mel: Derecho de alimentos como derecho humano y apremios para obtener el cumplimiento. Editorial Librotecnia, Santiago, 2019.

INSTITUTO NACIONAL DE ESTADÍSTICAS, 2017: Justicia. Informe anual 2017. Disponible en: https://www.ine.cl/estadisticas/sociales/ justicia.

MEDINA, Graciela: "Principios del Derecho de Familia". En: Revista de Derecho de Familia, volumen IV, N4, 2016.

NÚNEZ JIMÉNEZ, Carlos A.: "La obligación de alimentos de los abuelos. Estudio Jurisprudencial y dogmático". En: Revista Chilena de Derecho Privado, ํ21, 2013.

RAMOS PAZOS, Rene: Derecho de familia ( $7^{\text {a }}$ edición). Editorial Jurídica de Chile, Santiago, 2010.

SCHMIDT HOTT, Claudia y VELOSO VALENZUELA, Paulina: $L a$ filiación en el Nuevo Derecho de Familia. Editorial Lexis Nexis, Santiago, 2001.

VODANOVIC HAKLICKA, Antonio: Derecho de Alimentos. Editorial Lexis-Nexis, Santiago, 2004.

\section{Normas citadas.}

Código Civil.

Convención de los Derechos del Niño, adoptada con fecha 20 de noviembre de 1989. Publicada en Chile con fecha 27 de septiembre de 1990.

Declaración Universal de Derechos Humanos, adoptada con fecha 10 de diciembre de 1948.

Ley $\mathrm{N}^{\circ} 14.908$, sobre abandono de familia y. pago de pensiones alimenticias, publicada con fecha 30 de mayo de 2000. 
Pacto Internacional de Derechos Económicos, Sociales y Culturales, adoptada con fecha 19 de diciembre de 1966. Publicada en Chile con fecha 27 de mayo de 1989.

Proyecto de ley que Modifica el Código Civil, para eximir del pago de alimentos subsidiarios a los adultos mayores de la cuarta edad, Boletín $\mathrm{N}^{\circ} 12552-18$.

\section{Jurisprudencia citada.}

Corte de Apelaciones de Chillán, sentencia de fecha 01 de septiembre de 2005, rol 505-2005.

Corte de Apelaciones de Concepción, sentencia de fecha 13 de junio de 2008, rol 377-2008.

Corte de Apelaciones de Concepción, sentencia de fecha 23 de noviembre de 2009, rol 451-2009.

Corte de Apelaciones de Coyhaique, sentencia de fecha 17 de enero de 2011 rol 49-2010.

Corte de Apelaciones de Coyhaique, sentencia de fecha 12 de febrero de 2016, rol 35-2015.

Corte de Apelaciones de Coyhaique, sentencia de fecha 10 de junio de 2016, rol 9-2016.

Corte de Apelaciones de San Miguel, sentencia de fecha 01 de agosto de 2011, rol 449-2011.

Corte de Apelaciones de San Miguel, sentencia de fecha 20 de noviembre de 2015, rol 793-2015.

Corte de Apelaciones de Rancagua, sentencia de fecha 29 de octubre de 2018, rol 310-2018.

Corte de Apelaciones de Santiago, sentencia de fecha 21 de agosto de 2012, rol 43-2012.

Corte de Apelaciones de Santiago, sentencia de fecha 26 de abril de 2012, rol 26.04.2012.

Corte de Apelaciones de Santiago, sentencia de fecha 27 de diciembre de 2010, rol 1101.2010. 
Corte de Apelaciones de Valparaíso, sentencia de fecha 18 de junio de 2015, rol 309-2015.

Corte de Apelaciones, $R D J$, volumen LXXVIII, tomo I, $2^{\text {a }}$ parte, sección $2^{\mathrm{a}}, 1981$.

Corte de Apelaciones, Fallos del mes, $\mathrm{N}^{\mathrm{o}} 157$.

Corte Suprema, sentencia de fecha 30 de noviembre de 2006, rol 53562006.

Corte Suprema, sentencia de fecha 29 de febrero de 2012, rol 1044-2011.

Corte Suprema, sentencia de fecha 30 de octubre de 2012, rol 2416-2012.

Corte Suprema, sentencia de fecha 22 de enero de 2014, rol 6112-2013.

Corte Suprema, sentencia de fecha 10 de junio de 2014, rol 9596-2014.

Corte Suprema, sentencia de fecha 04 de agosto de 2014, rol 1617-2014.

Corte Suprema, sentencia de fecha 17 de diciembre de 2014, rol 217562014.

Corte Suprema, sentencia de fecha 15 de diciembre de 2015, rol 81292015.

Corte Suprema, sentencia de fecha 13 de enero de 2016, rol 10431-2015.

Corte Suprema, sentencia de fecha 21 de abril de 2016, rol 19.358-2016.

Corte Suprema, sentencia de fecha 31 de enero de 2017, rol 73910-2016.

Corte Suprema, sentencia de fecha 08 de febrero de 2017, rol 4345-2016.

Corte Suprema, sentencia de fecha 16 de marzo de 2017, rol 76375-2016.

Corte Suprema, sentencia de fecha 25 de enero de 2018, rol 39.744-2017. 
